\title{
La recuperación de la crónica y el perfil por parte de Julio Villanueva Chang, un neoconceptista del siglo XXI ${ }^{1}$
}

\author{
Ignacio López-Calvo \\ University of California, Merced \\ lopezcalvo@msn.com
}

«En tiempos de mayor inseguridad y confusión, una crónica ya no es tanto un modo literario y entretenido de "enterarse" de los hechos sino que sobre todo es una forma de "conocer" el mundo». Julio Villanueva Chang, «El que enciende la luz»

\section{RESUMEN}

Julio Villanueva Chang, uno de los autores sinoperuanos más internacionales, es también el último gran cronista de la tradición peruana. Por medio de sus crónicas y perfiles, «traduce» el mundo que lo rodea, a menudo tratando de expresar lo inefable por medio de paradojas, antítesis y contradicciones salpicadas de humor, ironía y quizá cierta resignación mal camuflada. Sus personajes son el reflejo de las relaciones humanas en los lugares en los que vive o que visita; al mismo tiempo, las ciudades que describe se hacen eco de las sorprendentes contradicciones de la naturaleza humana. Aunque muchos de los intereses del cronista muestra una mirada internacional, su Perú nativo continúa siendo uno de los principales marcos de referencia de su escritura. La prosa de Villanueva Chang es tan cautivadora porque muestra un espíritu de innovación y frescura, a la vez que se hace eco del ingenio y el carácter lúdico que caracteriza la prosa conceptista de Quevedo. Por esta razón, considero a esta figura clave en el rescate de la crónica y el perfil latinoamericanos un escritor neoconceptista.

1 Varios párrafos de este ensayo aparecen en mi libro Dragons in the Land of the Condor: Writing Tusán in Peru (University of Arizona Press, 2014). La versión inglesa del artículo se publicó en 2013 en Altertexto, nro. 3, pp. 2-15. 


\section{PALABRAS CLAVE}

Julio Villanueva Chang, crónica, perfil, neoconceptista.

\section{ABSTRACT}

Julio Villanueva Chang, one of the most international sinoperuvian authors, is also the last major historian of the Peruvian tradition. Through his chronicles and profiles, he «translates» the world around him, often trying to express the ineffable through paradoxes, antitheses and contradictions peppered with humor, irony and perhaps some bad camouflaged resignation. His characters are a reflection of human relationships in the places where he lives or visits; at the same time, the cities he describes echo the surprising contradictions of human nature. Although many of the interests of the chronicler shows an international look, his native Peru remains one of the major frameworks of his writing. Villanueva Chang's prose is so captivating because it shows an innovation and freshness spirit, while echoing the wit and playfulness that characterizes the conceptista prose of Quevedo. For this reason, I consider this a key figure in the rescue of chronic and neoconceptista profile, a Latin writer.

\section{KEY WORDS}

Julio Villanueva Chang, chronic profile, neoconceptista.

Julio Villanueva Chang (1967- ) es uno de los autores sinoperuanos más internacionales. Ha publicado Mariposas y murciélagos. Crónicas y perfiles (1999), una antología de sus crónicas publicadas en el periódico El Comercio entre 1994 y 1999, y Elogios criminales (2008), otra antología de siete perfiles publicados por Random House Mondadori, México. Es también el fundador y director de la revista Etiqueta Negra, a menudo considerada una de las mejores publicaciones intelectuales y literarias de Latinoamérica².

2 Julio Villanueva Chang nació en Lima, donde todavía vive. Estudió Pedagogía en la Universidad Nacional Mayor de San Marcos, y ha dado seminarios y charlas en varias instituciones, incluyendo Harvard, Yale, la Universidad de Barcelona, Columbia University y University of California, Merced. Ha ganado el Interamerican Press Association Award (IAPA) en «feature writing». Villanueva Chang dirige un taller sobre escritura de crónicas y periodismo literario en la Universidad Peruana de Ciencias Aplicadas (UPC). Sus textos han aparecido en varios 
La crónica en castellano, un género parecido al New Journalism de autores estadounidenses como Tom Wolfe, Hunter Thompson, Norman Mailer, Truman Capote y otros, es un género periodístico con una larga tradición tanto en España como en Latinoamérica. Villanueva Chang lo considera un subgénero literario. Quizá el padre de este subgénero sea el escritor satírico romántico español Mariano José de Larra (1809-1837). Varios autores modernistas, así como muchos de los críticos culturales latinoamericanos más importantes, han recurrido también a la crónica. Típicamente, la crónica enfatiza la interpretación subjetiva de los hechos por parte del cronista y viene marcada por la personalidad y el estilo personal del autor. Según Linda Egan ${ }^{3}$, se trata de un género literario aparte:

The chronicle is, clearly, related to the essay, but its distinctive textual persona feeds expectations that we will experience as something more than a lecturer sharing insights or recommendations on a significant current topic. We expect to be entertained and at the same time to be challenged in a peculiarly personal way, to be surprised by the crónica's excess. In this respect, the chronicle exceeds not only the generic limits of the essay but also of history, journalism, sociology, anthropology, metaphysics, comparative religion, philosophy, and other assertive genres.

Villanueva Chang, tras argüir que «cada día es más difícil saber lo que sabemos», añade una nueva impresión sobre las particularidades de la escritura de crónicas en su ensayo «El que enciende la luz»: «En el siglo XXI, un cronista ya no es solo un buen escritor de la información. Su desafío es ser un reportero y traductor de los acontecimientos [...] Su reto es narrar los hechos de tal forma que lleven a un lector a entender qué encierra un fenómeno y sus apariencias, pero tomándose la molestia de no aburrir con ello» ${ }^{4}$. A su juicio, la crónica es una manera de traducir el mundo. Esto se evidencia tanto en sus crónicas como en sus perfiles, que retratan la cara más humana y desconocida de personas que admira.

Como explica Fernando Iwasaki en su colección de ensayos Mi poncho es un kimono flamenco (2005), el Perú tiene una larga tradición de escritura de crónicas, con figuras como Héctor Velarde (1898-1989), «que nos enseñó a hacer el humor además de la guerra, pues la crónica literaria

periódicos y revistas de España y Latinoamérica, incluyendo El País, La Vanguardia, La Nación, Página/12, Reforma, Gatopardo, El Malpensante, Vogue, Marie Claire, Letras Libres, The Virginia Quarterly Review y World Literature Today. Cada domingo, publica una columna titulada «Horóscopo chino» en el diario español Público. La Asociación de Prensa de Aragón y el Congreso de Periodismo Digital de España publicaron una compilación de sus experiencias como editor titulada Un día con Julio Villanueva Chang.

3 Egan 2002: 117.

4 Extraje esta cita de la versión inédita de 2010 de este ensayo. 
peruana o tiene ironía o no es peruana» ${ }^{5}$. Menciona asimismo los libros del poeta Antonio Cisneros (1942- ): El arte de envolver pescado (1990), El libro del buen salvaje (1995) y Ciudades en el tiempo (2001); los de Abelardo Sánchez León (1947-): La balada del gol perdido (1993); los de Jorge Eslava (1953): Flor de azufre (1997); los de Jaime Bedoya (1965): ¡Ay, qué rico! (1991) y Kilómetro cero (1995). Acto seguido, presenta a Villanueva Chang como el último gran cronista de esta larga tradición peruana.

Normalmente, Villanueva Chang no se enfoca en gente o tópicos chinos en sus escritos. Uno de los pocos textos dedicados a este tema es su «Carta a mi abuelo chino. Un cantonés casero y querendón», publicada en el periódico El Comercio el 12 de octubre de 1999, mientras se celebraba en el Perú el sesquicentenario del comienzo de la inmigración china. Allí, utiliza la anécdota del centésimo aniversario del nacimiento de su abuelo para reflexionar sobre su propia herencia étnica china. De hecho, esta carta se puede considerar una suerte de modelo de lo que le ocurre a un tusán que redescubre su herencia china. Primeramente, Villanueva Chang informa a su ancestro de que su apellido -el más común del mundofue una fuente de insultos durante su infancia: le llamaban Chino. El autor confiesa que pasó diez años queriendo no ser sinoperuano, por lo que abría los ojos todo lo que podía. La mayoría de la gente, le recuerda a su abuelo, no sabe la diferencia entre las diferentes nacionalidades asiáticas, aun cuando las tradiciones chinas ya son parte de la cultura peruana: «No los culpo, abuelo: más allá de unos ojos rasgados, en todas partes ignoramos lo propio como lo ajeno. En Perú, todos hemos sorteado las primeras decisiones de nuestra vida a ese juego de manos infantil del yan-que-po, sin saber que en chino significan papel, piedra, tijera. Siempre nos hemos alimentado de maravillas sin saber de dónde vienen ${ }^{6}$.

Dirigiéndose a su abuelo por su apellido, Chang Ton, Villanueva Chang recuerda la historia personal de este como un cantonés adolescente aventurero que probó suerte en Lima y tuvo la suerte de llegar después de la primera ola de inmigrantes chinos, que fue explotada en los campos de guano y las plantaciones de caña de azúcar y algodón en condiciones de semiesclavitud. Aunque Chang Ton no sabía castellano, fue un gran calígrafo y cocinero. Administró también una tienda de fruta y dulces, y varios chifas, incluyendo el del Teatro Chino. Villanueva Chang alaba también el refinamiento de la cultura y comida chinas, señalando cómo medían el tiempo con un reloj de olores o mirando los ojos de los gatos. Acto seguido, se disculpa por no saber escribir en mandarín ni comer con palillos.

5 Extraje esta cita de la versión inédita de 2010 de este ensayo.

6 Extraje esta cita de la versión inédita de 2010 de este ensayo. 
Villanueva Chang explica que su abuelo, «como todos los chinos» ${ }^{7}$, era apostador. Incluso fue arrestado en una ocasión por jugar al juego de mesa chino mahjong ${ }^{8}$. Como representante de la comunidad china en Lima, Chang Ton dedicó su vida a resolver los problemas de otras personas. Villanueva Chang, al igual que en otros perfiles, menciona el horóscopo (esta vez la versión china) para señalar que nació en la provincia de Guangdong, en la China meridional, bajo el signo del cerdo, en 1899. Se nos informa, asimismo, de que fue dueño del primer televisor del barrio y de que, cuando se hizo católico, fue bautizado con el nombre de Carlos Alberto Chang Li. Después, el perfil lo describe como un chino muy extraño, por estar tan bien asimilado a la cultura peruana: «Bailabas marinera, foxtrot, vals. Tuviste más de cien ahijados de matrimonio y de bautizo. Hacías música con cucharas para acompañar a guitarras de una jarana criolla. Fuiste padrino de los equipos de fútbol más reputados del barrio. No te perdías una sola función de zarzuela ni de ópera» ${ }^{9}$. Villanueva Chang cierra el perfil mencionando que escuchó que su carismático abuelo era muy buena persona; no obstante, le reprocha el haber muerto dos años antes de que él naciera.

Villanueva Chang le escribe también una carta abierta a su madre, quien murió de cáncer, titulada «La indiscreción de asomarse por la espalda. Horóscopo chino». Comienza la carta con una anécdota nostálgica: cuando el cáncer no le permitía dormir por la noche, su madre se levantaba a ver lo que estaba escribiendo. A pesar de que esas visitas interrumpían su escritura para Etiqueta Negra, le permitían tener conversaciones más profundas con ella. Villanueva Chang describe cómo sufría su madre en aquellos días. El trabajo para la revista, añade, tenía beneficios terapéuticos para sobrellevar el dolor del fallecimiento de su madre. Fue ella la primera que se dio cuenta del amor del autor por la escritura; y le encantaba Etiqueta Negra, asegura el autor. Fue ella quien le familiarizó con la soledad que más tarde necesitaría para la escritura. Tras su muerte, recuerda el autor, se sintió culpable por todos los momentos que no pasó con ella, pero también empezó a recordar los momentos felices, como el día en que le dio un regalo relacionado con su amor a la lectura: el Libro Guinness de los récords.

Muchos de los perfiles y crónicas de Villanueva Chang describen tanto su propia personalidad como la del objeto de exploración. De hecho, a menudo usa al protagonista del perfil como pretexto para exponer verdades

7 Extraje esta cita de la versión inédita de 2010 de este ensayo.

8 La palabra mahjong es una adaptación al castellano de la palabra china Machiok.

9 Extraje esta cita de la versión inédita de 2010 de este ensayo. 
más profundas. Por otra parte, un perfil más reciente provee valiosa información sobre su idea de la escritura de crónicas: «Un chofer de ambulancia que llegaba a tiempo», publicado en el diario español El País el 16 de junio de 2011. Confiesa allí su admiración por las crónicas y perfiles de Hemingway, y destaca las principales virtudes de su estilo literario, incluyendo su habilidad para presentar una vista panorámica a la vez que cuida el detalle. Hemingway, arguye Villanueva Chang, era capaz de saltar de la fisionomía del personaje a la historia. Su estilo periodístico optaba por la simplicidad: «Hemingway repetirá una y otra vez su agradecimiento con las normas de estilo del Kansas City Star, donde publicó una docena de textos en los que predominan las frases breves y la austeridad en los adjetivos, al punto de atribuirle una gran deuda en su oficio de escribir» ${ }^{10}$. Otra de las cosas que admira de Hemingway es el profundo conocimiento que tenía de los temas que trataba y su gran esfuerzo para explicar, como testigo, lo que no aparecía plenamente en la prensa tradicional. Otra de las virtudes de Hemingway - que, a mi juicio, Villanueva Chang comparte con él- es su habilidad para autorretratarse, así como para describir tragedias por medio de sus personajes. Esto se evidencia, por ejemplo, en «Los choferes de Madrid», donde Hemingway recrea la atmósfera de la ciudad durante un bombardeo de 19 días por medio de dichos choferes, usando un humor negro y un estilo animado. Como se señaló anteriormente, en mi opinión, estos rasgos del estilo narrativo de Hemingway que celebra Villanueva Chang se podrían atribuir fácilmente a su escritura también.

Si bien el enfoque de Elogios criminales son las figuras públicas nacionales e internacionales, en Mariposas y murciélagos, que Fernando Iwasaki describe como un «retablo de personajes patéticos, melancólicos y valleinclanescos» ${ }^{11}$, Villanueva Chang se concentra, más bien, en ciudadanos de a pie, ofreciendo crónicas y perfiles interesantes de la vida diaria peruana. Uno de ellos es el perfil que abre el libro, «La vida es una pose», cuyo protagonista es Rodolfo Muñoz del Río, probablemente el modelo profesional más viejo del mundo. Durante 50 años, este Narciso de 66 años ha posado para generaciones de alumnos de la Escuela Nacional de Bellas Artes. El máximo esfuerzo a lo largo de su vida, exagera Villanueva Chang usando una de sus típicas paradojas, «ha consistido en tratar de no hacer nada» ${ }^{12}$. «En sus ratos libres, se viste», bromea el autor. El cronista describe la tristeza de Muñoz del Río cuando robaron de su apartamento un largo espejo y todos los retratos de él que guardaba, así como los

10 Villanueva Chang 2011, 16 de junio.

11 Extraje esta cita de la versión inédita de 2010 de este ensayo.

12 Villanueva Chang 1999: 17. 
trucos que usó para hacer creer a su familia que era profesor de dibujo en la escuela. Curiosamente, se nos informa de que con frecuencia los alumnos le piden consejo cuando lo retratan. El orgulloso modelo, leemos, sabe que no solo es el más viejo, sino también el mejor. Es consciente, asimismo, de su inmortalidad: «Pero yo no moriré nunca, advierte este último modelo, porque en el mundo entero hay pinturas y esculturas con $\mathrm{mi}$ rostro y mi cuerpo» ${ }^{13}$.

El perfil que cierra la colección, «El pitazo final», está dedicado al elegante Reynaldo Nonone, un alto policía de tráfico afroperuano que acaba de morir. Según declama Villanueva Chang con su cautivadora y humorística prosa, todo el mundo respetaba a Nonone, quien llevaba a cabo su labor con la gracia de un torero o un director de orquesta. Otros compatriotas, continúa el cronista, aseguran que tenía «la elegante autoridad que hubiésemos querido tener en todo el país» ${ }^{14}$ e incluso el cardenal del Perú llegó a predicar que todo el mundo debería ser como él. En una ocasión, este "diplomático de la esquina» ${ }^{15}$, como lo bautiza Villanueva Chang, se atrevió a parar al presidente Odría por no respetar un semáforo en rojo. Su fama acabaría por llevarlo a actuar como él mismo en un corto y más tarde a aparecer como extra en una película estadounidense protagonizada por John Wayne. Alfredo Bryce Echenique lo incluyó como personaje en una de sus novelas. Hacia el final de su vida tuvo otros empleos y trabajó hasta los 80 años, manteniendo en todos ellos la misma elegancia de siempre. Ahora, tras su muerte, Villanueva Chang afirma: «Se fue a dirigir el tránsito a otra parte» ${ }^{16}$. Otras crónicas hablan del dentista de Gabriel García Márquez; la historia de un pescador que se hizo millonario; de un hombre que caminó a lo largo de toda la costa peruana en 90 días; de los accidentes de tráfico provocados por una valla publicitaria con una hermosa modelo en ropa interior; de las preguntas políticamente incorrectas que le hizo Mario Vargas Llosa al escritor cubano Ronaldo Menéndez, y las memorias del Nobel peruano acerca de La Habana y sus escritores; o de la historia de una alemana, experta en mariposas y murciélagos (de ahí el título de la colección de ensayos), que fue la única sobreviviente de un accidente de avión en la selva peruana en 1971. Con solo 17 años, caminó sola a lo largo del río Amazonas durante nueve días hasta que dio con unos leñadores locales. En el accidente perdió a su madre, pero entre las cosas que más le duelen todavía están los artículos sensacionalistas que escribió la prensa tras el accidente. 
Una de las mejores crónicas de la colección es «Viaje al centro de la noche», con la que ganó en 1995 el Premio de la Sociedad Interamericana de Prensa. Allí, Villanueva Chang describe el submundo de alcohólicos y prostitutas que drogan y roban a sus clientes que se ve en el centro de Lima de noche. Nos habla también de un joven de 16 años que escribe poesía y canta en los autobuses de la ciudad, para ir a dormir cada noche junto a la puerta del edificio donde, con solo unos cuantos meses, lo abandonó su madre. Con su típico sarcasmo, Villanueva Chang concluye el perfil afirmando: «Si como antaño las calles de Lima se bautizaran según los oficios que predominaran en ellas -Bodegueros, Espaderos, Mercaderes-, el jirón Cailloma sería hoy Prostitutas, y Quilca, la popular calle Borrachos» ${ }^{17}$.

Pero quizá sus más brillantes crónicas y perfiles aparecen en Elogios criminales. Dos de los siete perfiles sobre personajes públicos incluidos en esta colección, los que hablan de García Márquez y del director de cine alemán Werner Herzog, son versiones revisadas de los textos originales incluidos en Mariposas y murciélagos. En el prólogo, John Lee Anderson llega a la conclusión de que «en estos perfiles ha emergido con nuevas verdades sobre sus personajes y también - quizá- sobre la naturaleza humana» ${ }^{18}$. "García Márquez va al dentista» abre la colección preguntando en su subtítulo: « ¿Qué busca un Premio Nobel con caries en un odontólogo de provincias?» ${ }^{19}$. Supuestamente, el perfil es la respuesta a esta pregunta. En contraste con el resto de los textos de la colección, no es el resultado de una entrevista con la figura pública sino con su dentista, quien recuerda sus experiencias con el gran maestro del realismo mágico. Villanueva Chang, consciente del hecho de que el escritor colombiano raramente concedía entrevistas, optó por verlo a través de los ojos del dentista. La primera frase describe una escena desmitificadora: el doctor Jaime Gazabón abre la puerta y encuentra a García Márquez «tan solo como un astronauta en su sala de espera» ${ }^{20}$. El autor de Cien años de soledad llegó a tiempo aquella tarde, al igual que lo hizo en el resto de las citas médicas. Varias frases del primer párrafo son indicativas del estilo original y sugerente del cronista: «unas cuantas revistas para bostezar la espera»; «sus anteojos de lector de dentaduras»; «y unos bigotes que se esmeraban por competir con su sonrisa simétrica» ${ }^{21}$. Y con su usual ironía e ingenio, Villanueva Chang menciona que el despacho del doctor está ubicado en el área perfecta: el barrio Bocagrande.

17 Villanueva Chang 1999: 122.

18 Villanueva Chang 2008: 9.

19 Villanueva Chang 2008: 11.

20 Villanueva Chang 2008: 11.

21 Villanueva Chang 2008: 11. 
Seguidamente, un resumen de la historia médica de García Márquez muestra el gran sentido del humor del colombiano. Por encima de todo, el perfil lo retrata como un hombre campechano y agradable que salió de la casa del dentista por la cocina para conocer a los sirvientes y preguntar "con el entusiasmo de un cura recién ordenado» ${ }^{22}$ cuándo era el bautismo del hijo del dentista para ser el padrino. Curiosamente, la ceremonia del bautismo acabó siendo macondiana, según el doctor Gazabón. A medida que avanza el perfil, Villanueva Chang va insertando información sobre la juventud del autor colombiano, su rechazo a las entrevistas y otras anécdotas que muestran su faceta más humana, alejándolo así de su estatura casi mítica. Otros párrafos dirigen su mirada al dentista, relatando cómo aquella inesperada visita cambió su vida: por ejemplo, le empiezan a invitar a leer fragmentos de Cien años de soledad y sus amigos le envían libros de García Márquez para que se los firme. Su fotografía con el célebre novelista, imagina Villanueva Chang, «parecía servir al dentista como una primera anestesia para sus pacientes $»^{23}$.

La segunda de las cinco partes del perfil presenta a Villanueva Chang mismo como personaje. Cinco años después del primer encuentro con el dentista, vuelven a verse en Florida, después de que la familia tuviera que dejar el país por miedo al grupo terrorista Fuerzas Armadas Revolucionarias de Colombia (FARC), que no aprobaba sus prédicas evangelistas en barrios populares. El doctor Gazabón, que ahora tiene que trabajar como ceramista dental, le muestra al cronista una maleta negra con un secreto: como en el suspenso de una novela, el lector no averigua hasta la quinta parte del perfil que la maleta contiene una bolsa de terciopelo con una de las muelas de García Márquez con un empaste de oro.

Las partes tres y cuatro revelan las razones por las que García Márquez acabó visitando al dentista. Como es típico en los perfiles de Villanueva Chang, utiliza diferentes nombres para referirse a su objeto de estudio. A veces, García Márquez se convierte en «el hijo del telegrafista» ${ }^{24}$, tal y como este se describió a sí mismo en la hoja con el historial clínico que rellenó en su primer visita a la oficina del dentista y en su novela El amor en los tiempos del cólera (1985). Averiguamos también que aunque García Márquez era aún más humilde cuando hablaba de política, se negaba tajantemente a hablar de Dios. En la cuarta parte, el odontólogo especula que García Márquez lo había escogido como compadre «para romper la rutina de famoso. Hablaba del escritor con familiaridad, admiración y sin 
falsas reverencias. "La gente — me dijo- se olvida de que Gabo es un ser humano"»25. La apreciada muela es, en sí misma, otro memento del Leitmotiv del perfil: en el fondo, el genial autor colombiano no es otra cosa que un ser humano más. Irónicamente, al igual que el malvado alcalde se sintió indefenso en la oficina del dentista autodidacta en el cuento de García Márquez «Un día de estos»: así encontramos también al Nobel colombiano en la oficina que tiene el doctor Gazabón en Bocagrande. Pero esta vez se le da un giro a la escena: «El molar de un genio se ve tan espantoso como el de cualquiera y crea la ilusión de que todos somos iguales bajo las tenazas de un dentista. Pero una muela de García Márquez en tus manos es más que eso. Es la historia secreta de una sonrisa» ${ }^{26}$. Al final del perfil, el doctor Gazabón afirma: «Gabo sabe que yo no puedo esconder lo que pasó entre nosotros» ${ }^{27}$. No obstante, como reveló Villanueva Chang en nuestra entrevista, García Márquez nunca le perdonó al dentista que revelara la información incluida en el perfil. Las frases finales muestran la misma ironía que marca los otros textos de la colección: «desde esa primera cita hubo una pérdida. En la historia de la literatura, siempre ha sucedido: Homero fue ciego, a Cervantes le faltaba un brazo, García Márquez tenía caries» ${ }^{28}$. Pero quizá lo más paradójico del perfil es el hecho de que el célebre escritor buscara ávidamente la amistad de un dentista de provincias.

El título del segundo perfil de la colección, «El tenor que no sabía silbar», ejemplifica las típicas paradojas, contradicciones y antítesis (quizá un atavismo heredado de la poesía barroca) que Villanueva Chang, una especie de neoconceptista del siglo XXI, busca en su escritura. El subtítulo pregunta: «¿Por qué uno de los divos más revoltosos de la ópera se porta tan bien en casa de su mamá?» ${ }^{29}$. Los dos primeros párrafos subrayan los elogios recibidos por Juan Diego Flórez, el tenor peruano que por aquel entonces tenía 33 años. En el tercer párrafo, Villanueva Chang se incluye a sí mismo como entrevistador en la narrativa. Al igual que en el perfil anterior, es evidente desde las primeras líneas que el objetivo principal es revelar el ser humano detrás de la celebridad: «Era un escenario extraño para escuchar por primera vez a un tenor famoso, pero una circunstancia conveniente para empezar a conocer a un hombre: Juan Diego Flórez estaba en casa de su mamá» ${ }^{30}$. En consonancia también con los perfiles mencionados, el lector conoce la personalidad de la estrella de ópera 
gracias a los comentarios de parientes y amigos: por ejemplo, uno de sus amigos de la infancia le cuenta a Villanueva Chang — de nuevo otra paradoja - que el tenor jamás aprendió a silbar. Otros amigos, así como su madre, recuerdan lo travieso que era de niño. En contraste, el día de la entrevista, en el estado de Florida, el tenor es parco en palabras y muestra gran tranquilidad: respondía a las preguntas de una manera monótona que revelaba su timidez o aburrimiento. Nos enteramos así de que el energético tenor queda en stand-by cuando no está cantando. De hecho, Flórez desearía tener una vida más normal, con una familia y más tiempo para pasar en casa. En contraste, de niño, a este tenor formal y recatado le encantaba imitar a los profesores, así como a los cantantes y actores famosos, y se divertía también cantando ópera en los autobuses peruanos.

Para profundizar en la personalidad del tenor, Villanueva Chang presenta la imagen que tiene su exnovia de la relación entre Flórez con su madre, María Teresa Salom. Saltando de la paradoja a la ironía, el autor señala que la cara de Flórez aparece en un sello peruano ahora que «la gente ya no escribe cartas» ${ }^{31}$. Igualmente irónico es el hecho de que aunque los peruanos reconocen el rostro de Flórez, casi nadie lo ha escuchado cantando. Como dijo una vez el escritor español Jacinto Benavente, «la ironía es una tristeza que no puede llorar y sonríe». Y la ironía continúa por medio de símiles cuando se nos informa de que el tenor peruano no canta en la ducha ni es un fanático de la música: «Un tenor fuera de serie que no es fanático de la música es como un eximio escalador del Himalaya que le teme a las alturas» ${ }^{32}$. Estas anécdotas dan paso finalmente al análisis de la psicología nacional peruana: «Pero en un país con una famélica autoestima por tantas derrotas históricas, un cantante de ópera puede acabar por convertirse en un asunto patriótico. Es un vencedor $\rangle^{33}$. En consonancia con su tono humorístico, Villanueva Chang continúa con su tono satírico al afirmar que la popularidad de la ópera en Perú está al mismo ínfimo nivel que la del presidente Alejandro Toledo. Luego acusa cómicamente al tenor de no ser capaz de distinguir entre el bien y el mal: le gusta en sentido de la melodía que tiene Julio Iglesias. El perfil concluye volviendo a la ironía anunciada en el título (Flórez es un tenor que no sabe silbar) y revelando que su cara más humana: el sueño del cantante de ópera es tener un hijo.

La tercera crónica de la colección es «El $A B C$ del señor K», subtitulada «¿Qué leerá un corresponsal de guerra cuando va a la cama?». Se trata 
del resultado de una breve conversación con el reportero polaco Ryszard Kapuściński (o Kapucinski, como lo escribe el autor; 1932-2007) sobre sus primeras lecturas. Como el reportero, cuyas mejillas rojizas están «en estado de pudor crónico» ${ }^{34}$, solo tenía unos minutos antes de su vuelo, este texto es mucho menos detallado que los otros incluidos en la colección. Villanueva Chang presenta a este autor del «reportaje literario» o reportage d'auteur (para usar el término acuñado por el propio Kapuściński) como el reportero superstar del Tercer Mundo y como el autor de El emperador, un texto sobre el declive del régimen del emperador etíope Haile Selassie. Llegado a un punto del perfil, Villanueva Chang confiesa que todo lo que le dice Kapuściński le parece excesivo. Por ejemplo, en preparación para la escritura del libro Ebony, leyó 200 libros sobre asuntos africanos; igualmente, leyó 14 mil páginas para escribir otro libro sobre Crimea; y dado que cuando está trabajando nunca hace llamadas telefónicas ni escribe cartas ni correos electrónicos (no necesita el internet), una vez pasó 50 meses sin comunicarse con su esposa. Como muchos otros protagonistas de los perfiles de Villanueva Chang (y en esto coincide con su compatriota Mario Vargas Llosa), Kapuściński está obsesionado con su profesión: el periodismo es su misión en la vida y se siente culpable cuando no está escribiendo. Villanueva Chang describe también al reportero polaco como «uno de los últimos dinamiteros de las fronteras de género» ${ }^{35}$ : no cree en los géneros literarios tradicionales.

Mientras que en el perfil anterior nos enteramos de que el sueño de Flórez era tener una familia, aquí vemos que Kapuściński siempre quiso ser filósofo. La crónica también ofrece los consejos que da el escritor polaco sobre la escritura, que, una vez más, coinciden con el estilo del propio Villanueva Chang: «sus libros están plagados de moscas literarias que sobrevuelan los ojos de sus lectores distrayéndolos de la tensión de una escena trágica [...] La altura asfixia y de vez en cuando hay que descender para encontrar un respiro» ${ }^{36}$. En la escritura de Villanueva Chang, por cierto, estas moscas literarias son precisamente los comentarios humorísticos, sus paradojas e ironías, así como las referencias literarias.

El siguiente perfil, «El alcalde ciego» ${ }^{37}$, es uno de los más largos de la colección (76 páginas), seguido de cerca del dedicado a Ferran Adrià, el célebre chef catalán y dueño del restaurante elBulli (de 74 páginas). En el primero, encontramos la faceta más humana de Apolinar Salcedo (1955- ),

34 Villanueva Chang 2008: 46.

35 Villanueva Chang 2008: 51.

36 Villanueva Chang 2008: 54.

37 Este perfil, titulado en castellano «El alcalde ciego», se tradujo como «Through the Eyes of a Blind Mayor» al publicarse en The Virginia Quarterly Review. 
el exalcalde de Cali, que es ciego y afrodescendiente, y fue destituido por la Procuraduría General de la Nación en Colombia seis meses después de que lo entrevistara Villanueva Chang. La primera pista sobre la personalidad del exalcalde que se nos ofrece es que, guiado por la vanidad, usa gafas graduadas. Más pistas: cree en la astrología como si fuera una ciencia y cuenta con una «astróloga de cabecera» ${ }^{38}$, en lugar de un médico de cabecera; el reverso de su tarjeta de visita incluye versos del poeta uruguayo Mario Benedetti; $y$, aun cuando nunca ha visto las calles de Cali, su mapa mental de la ciudad le permite dar direcciones a su conductor. Más adelante, Salcedo condena la ubicua discriminación contra las personas con discapacidades físicas: «Una de las formas de desprestigiar mi gobierno es tratar de demostrar que la ceguera es una incapacidad y no solo una limitación ${ }^{39}$. Recuerda también con indignación cómo un hombre trató de «alquilarlo» para usarlo como mendigo.

Villanueva Chang ofrece sus primeras impresiones: «El alcalde de Cali era tan simpático que al conocerlo uno podía creer casi de inmediato en su inocencia y comenzar a sospechar de sus consejeros de gobierno» ${ }^{40}$. En cambio, unas líneas más tarde enumera los casos de corrupción de los que se acusa al exalcalde. Al final, el lector se da cuenta de que el perfil está dedicado tanto a Salcedo como a la ciudad de Cali con su basura, baches, atascos de tráfico, mendigos, narcotraficantes, guerrilleros, paramilitares, reinas de belleza y políticos y policías corruptos. El texto reflexiona sobre los contrastes sociales entre los barrios ricos de Ciudad Jardín, supuestamente habitados por narcotraficantes y cirujanos plásticos, que Salcedo raramente visita, y las barriadas creadas por gente desplazada por una guerra civil de medio siglo, que sí visita frecuentemente. En definitiva, el perfil analiza Colombia en general, incluyendo el problema del narcotráfico, la larga historia de violencia y la tolerancia hacia la criminalidad, el origen de la guerrilla de las FARC y otros temas relevantes. En último término, tanto Cali como Colombia acaban por convertirse en un microcosmos de Latinoamérica: «¿Por qué la gente decidió votar por un hombre ciego? Parecía la historia de siempre en América Latina: David contra Goliat, independientes versus políticos profesionales, humildes versus soberbios» ${ }^{41}$. Más tarde, se nos enseña que ser una buena persona no es recomendable para un político latinoamericano y que «la seriedad no es carismática en América Latina. No se ganan votos por ser serio» ${ }^{42}$. Incluso el «alcalde

38 Villanueva Chang 2008: 71. 39 Villanueva Chang 2008: 60. 40 Villanueva Chang 2008: 63. 41 Villanueva Chang 2008: 69. 42 Villanueva Chang 2008: 70. 
junior» de Cali se convierte en «la parodia adolescente de un tradicional político latinoamericano» ${ }^{43}$. Lo único que falta en el comportamiento de este joven, bromea Villanueva Chang, es que todavía no ha comenzado a robar. Así pues, como se afirmó anteriormente, la figura del alcalde es una excusa narrativa para hablar de la psicología nacional colombiana, la corrupción y la política latinoamericana.

Tras describir la prodigiosa memoria de Salcedo (que ha memorizado aproximadamente 500 números telefónicos), su mapa mental de Cali y su habilidad para jugar al fútbol, Villanueva Chang recurre a otra antítesis para preguntar: «¿Por qué entonces parece tan extraviado en la política?» ${ }^{44}$. Otros contrastes humorísticos describen su historia personal: «En las calles de Cali, algunos habían creído que el alcalde era el Mesías. Después algunos creyeron que era uno de los ladrones. En ambos casos lo crucificaron $»^{45}$. Pero para continuar con la exploración de la cosmovisión del alcalde, leemos que no tolera la compasión por su discapacidad física o los supuestos intentos de protegerlo, cuando en realidad están tratando de recibir favores a cambio. El autor también compara a Salcedo con el «niño alcalde» de Cali, así como con otras figuras públicas ciegas, como el expresidente Joaquín Balaguer (1906-2002), que fue una figura central en la política dominicana durante más de seis décadas y sirvió siete mandatos como presidente durante los periodos1960-1962, 1966-1978 y 1986-1996. Nuevas paradojas siguen abriendo puertas al pasado y el presente de Salcedo: aunque lo pusieron a cargo de castigar a los contrabandistas de tabaco y licor que estaban causando ceguera en la gente en Cali, la gente siente lástima por los narcotraficantes, pero no por Salcedo. Por lo que respecta a la cara más íntima del alcalde, el perfil destaca su amor por la pesca, su naturaleza sentimental y su miedo a acabar solo. Aunque el gran sueño de Salcedo es trabajar para la paz mundial como líder internacional, los residentes de Cali aseguran que el exalcalde está involucrado con la mafia local y que fomentó el clientelismo político y la corrupción durante todo su mandato.

El siguiente perfil, que trata del enigmático director de cine alemán Werner Herzog (1942- ), es el más corto de la colección. Su título es «El cineasta invisible» y el subtítulo es «¿Puede ser tan callado un director que amenaza de muerte a su actor favorito?». Al contrario que los otros perfiles, este incluye un epígrafe del actor favorito de Herzog, Klaus Kinski: «Herzog es un individuo miserable, rencoroso, envidioso, apesta a codicia

43 Villanueva Chang 2008: 93. 44 Villanueva Chang 2008: 75. 45 Villanueva Chang 2008: 82. 
y ambición, maligno, sádico, traidor, chantajista, cobarde y un farsante de la cabeza a los pies» ${ }^{46}$. En contraste con los otros textos, a causa de la brevedad de la entrevista que dio origen al escrito, este no se acerca a la cara humana del personaje analizando sus propias palabras. En realidad, se trata más bien de una suma de anécdotas sobre Herzog. Villanueva Chang conoció al director cuando se hallaba en el Perú filmando un documental titulado Alas de esperanza sobre Juliane Koepcke, la única sobreviviente de un accidente de avión en la selva peruana. Entre otras anécdotas, Villanueva Chang menciona que Herzog estaba en la lista de espera de ese mismo vuelo, que caminó de Alemania a Albania y a París, que una vez hipnotizó a sus actores durante el rodaje de Heart of Glass (1976) y que hizo que una tribu indígena cargara un barco a través de una montaña porque odia los efectos especiales.

El perfil que cierra la colección es también uno de los mejores: «Un extraterrestre en la cocina ${ }^{47}$, dedicado al conocido chef catalán Ferran Adrià (1961- ) y subtitulado «¿Cuántos platos debe romper un cocinero para convertirse en el chef más revolucionario del planeta?» ${ }^{48}$. Aparece dividido en dos partes, «Viaje a elBulli 2000» y «Viaje a elBulli 2007». Villanueva Chang comienza con la enumeración de las etiquetas que los críticos culinarios han puesto a la cocina de Adrià (de todas ellas, el catalán solo acepta la de «cocina tecnoemocional $\left.»^{49}\right)$. Concluye que el chef «parecía víctima de una conspiración internacional de alabanzas ${ }^{50}$ y se pregunta si hay «un idilio entre Adrià y la prensa mundial $»^{51}$. Tras describir unas cuantas anécdotas, incluyendo la vez en que el chef rechazó un cheque en blanco ofrecido por un magnate asiático por cocinar para él en una fiesta del fin del milenio, Villanueva Chang describe su visita a elBulli, el restaurante de este "genio de carne y hueso (y sal al gusto)» ${ }^{22}$. Para comenzar, describe su ubicación escondida y lejana, y las razones por las que Adrià lo prefiere así: «en los restaurantes de las ciudades la gente se junta más para hablar de negocios que para disfrutar de la gastronomía» ${ }^{53}$. Más adelante, el autor revela los orígenes del nombre del restaurante y describe su cocina, que, según él, parece más bien una sala de cirugía. En las siguientes páginas pasa a la fisionomía de Adrià: «Su frente es como un campo de concentración de tres arrugas, que se expande hasta una mata de cabello negro

46 Villanueva Chang 2008: 135.

47 Villanueva Chang 2008: 143. 48 Villanueva Chang 2008: 143. 49 Villanueva Chang 2008: 181. 50 Villanueva Chang 2008: 144. 51 Villanueva Chang 2008: 147. 52 Villanueva Chang 2008: 147. 53 Villanueva Chang 2008: 148. 
domesticado. Para un fisonomista gnóstico, tres arrugas en la frente son el rastro indudable de un artista» ${ }^{54}$.

Aunque Villanueva Chang se refiere al chef como el Gran Jefe, el Extraterrestre y Dios, enfatiza su «humildad con alma de lavaplatos»" vano, espera a la cola con el resto de sus empleados para que le sirvan el almuerzo. Se lo describe también como un hombre hiperactivo («Adrià es tan inquieto que parece estar siempre en otra parte $\aleph^{56}$, que trabaja más de 15 horas al día y da órdenes como si fuera un agitador político. Alaba, en particular, su descubrimiento de nuevas recetas por medio del juego y del humor: inventa técnicas para jugar con las emociones de sus clientes. Por medio de símiles, el autor describe la frenética actividad de los cocineros en la cocina: en sus propias palabras, parecen elegantes actores de teatro de vanguardia pero se mueven como bailarinas; parece que están operando a microbios en platos de diseño. La última sección de la primera parte del perfil revela que cada otoño Adrià cierra elBulli para dedicar todo su tiempo a su taller de investigación en Barcelona; de esta manera, su cocina puede seguir evolucionando de manera revolucionaria. Villanueva Chang describe el taller donde Adrià colabora con su hermano y mano derecha Oriol Castro como el laboratorio de un alquimista.

La segunda parte trata de su segunda visita al restaurante en 2007. En la primera escena, a uno de los cocineros de Adrià se le cae un plato, lo que se considera un tabú en elBulli, según Villanueva Chang. Más tarde, se recuerda que cuando la feria alemana de vanguardia honró a Adrià como invitado especial con uno de sus platos, este simplemente ofreció una reserva para dos a su restaurante. Entre otras cosas, el polifacético Adrià es escritor, dirige una fundación dedicada a mejorar los hábitos alimenticios de los niños, tiene múltiples contratos publicitarios y es dueño de una compañía de servicio de banquetes a domicilio. Como es típico de los perfiles de Villanueva Chang, luego de mencionar que según otro chef español ir a elBulli para un cocinero es como ir a Disney World, se refiere al chef en el siguiente párrafo como Mickey Mouse. Seguidamente, pasa a la vida privada del chef: en casa disfruta sentándose en el sofá sin pensar en nada y, mientras que el tenor Juan Diego Flórez no sabe silbar, a Ferran Adrià no le gusta el vino. Entre otras anécdotas, el perfil menciona que cuando Adrià contesta preguntas de periodistas de todo el mundo, lo hace como si estuviera jugando varias partidas de ajedrez simultáneas en las que él es el rey. En palabras del chef, disfruta dando entrevistas porque 
le ahorran dinero en terapia psicoanalítica y le ayudan a descubrir cosas sobre sí mismo a las que luego puede recurrir en su taller de investigación, en el que curiosamente trabaja un químico.

Villanueva Chang resume la experiencia de comer en elBulli en dos frases: "Adrià había hecho de los puntos suspensivos un ingrediente de su cocina. Cuando vas a elBulli no sabes qué vas a comer ni qué va a suceder $\rangle^{57}$. Volviendo a incluirse a sí mismo en la narrativa, confiesa lo poco que sabe de la extravagante cocina de Adrià: «Un par de expediciones a su restaurante en siete años eran mi certificado de ignorancia» ${ }^{58}$. Pero él no es el único; en su opinión, solo una de cada mil personas que citan a Adrià ha visitado el restaurante y solo uno de cada mil que ha ido entiende su cocina. Así, el autor se pregunta, quizá con falsa modestia, por qué un hombre que no sabe cocinar como él ha sido invitado a comer en elBulli, cuando se rumorea que incluso Bill Gates fue incapaz de conseguir una mesa en el mismo restaurante. Después, procede a confesar que fue mera suerte: alguien acababa de cancelar la reserva.

El perfil también se hace eco de la polémica crítica del chef tradicionalista Santi Santamaría de la cocina de vanguardia de Adrià en 2007. Tras describir los platos que se sirvieron en su cena por «orden de desaparición ${ }^{59}$, Villanueva Chang intenta definir la cocina de Adrià: «es genial, graciosa, descarada, extraña, revolucionaria, metafísica, chiflada» ${ }^{60}$. Después, el autor tacha de falsas las acusaciones contra Adrià, que considera resultado de la envidia: «No fui envenado ni el espectáculo superó al sabor. Solo me sentí agradecido» ${ }^{61}$. Cierra el perfil la historia de Pascal Henry, un gourmet suizo que misteriosamente desapareció después de comer en elBulli.

El último perfil que analizaré será «We're not in Kansas anymore», con título en inglés pero escrito en castellano e incluido en la colección Se habla español. Voces latinas en USA (2000). Está dedicado tanto a Mandalit del Barco, una cronista estadounidense que escribe para la National Public Radio de Kansas y que fue al Perú a filmar un documental, como a los contrastes entre el Perú y Estados Unidos. Por ejemplo, Villanueva Chang describe, con su típica ironía, la muerte de un peruano «en una de esas curvas del Perú donde los viajeros acostumbran a morir» ${ }^{62}$. Acto seguido, se mofa de la cultura estadounidense afirmando que conoció a esta mujer en Lima, donde las invitaciones a fiestas no incluyen una hora de llegada y 
otra de salida: «estábamos en Lima, donde el tiempo es de mentira» ${ }^{63}$. Con el mismo tono humorístico, tras afirmar que Del Barco tiene una madre mexicoamericana y un padre peruano, el autor señala que su nariz apunta «rumbo a los Andes» ${ }^{64}$.

Del Barco viaja a la ciudad de Ayacucho, donde el grupo terrorista Sendero Luminoso asesinó a tres de las mujeres de su familia: su abuela paterna, su tía y su prima. En el Día de los Muertos, contrata a personas para que lloren y recen en quechua por sus familiares. El Perú que descubre durante su viaje es muy diferente del país mítico que había imaginado: «Ella ha encontrado un paisaje real maravilloso minado por el trauma de su conquista española, la resaca de Sendero y una pigmea autoestima histórica» ${ }^{65}$. Villanueva Chang, que anteriormente había comparado a Del Barco con Dorothy, el personaje de The Wizard of $\mathrm{Oz}$, se refiere ahora a ella lúdicamente como Dorothy, imaginando que también ella sueña con viajar al otro lado del arco iris, donde se encuentra el Perú. Y una vez más, compara al Perú con Baldwin (Kansas), donde creció Del Barco: «En Baldwin no había ladrones ni asesinos [...] Allí matar no era una costumbre» ${ }^{66}$.

Otro pasaje revela que Del Barco es descendiente de Pedro del Barco, que luchó contra el rebelde Manco Inca y fue también uno de los fundadores de Cusco, y de Martín del Barco, un poeta español del siglo XVI. Después, Villanueva Chang enumera las ciudades en las que ha vivido Del Barco. Se mudó primero a Miami, «una gusana quinceañera con sueños de jet set» (197), a trabajar en el Miami Herald. Allí fue violada dos veces por un hombre, pero la Policía se negó a creerle. Más tarde, se mudó a Washington, una ciudad que «le aburría con su alma suiza» ${ }^{67}$, para trabajar en la National Public Radio. Del Barco finalmente se mudó a Los Ángeles, donde experimentó un terremoto de nivel siete. En la actualidad vive en otra ciudad en la que nunca llueve: Lima. Desde su ventana puede ver la calle Tarata, donde Sendero Luminoso mató a 25 personas e hirió a 200 más. A Del Barco le sorprende la prominencia de la prensa amarilla peruana que, según Villanueva Chang, aliena a la población, la mitad de la cual sobrevive con dos dólares al día. El perfil termina con Del Barco llorando como no había llorado nunca: la Policía está lanzando gas lacrimógeno a la oposición a Fujimori. Además, tiene que evitar a los machistas que le silban por la calle y a los estafadores que tratan de engañar a los turistas. Pero, por encima de todas estas anécdotas, el perfil presenta una 
imagen deprimente de Lima, una ciudad que, como el autor nos recuerda, fue descrita por Melville en Moby Dick como «the strangest, saddest city thou can'st see», y por el poeta y pintor limeño César Moro como «Lima, la horrible». El perfil de la cronista de Kansas acaba convirtiéndose en una excusa para lamentar los problemas sistémicos de Lima y Perú.

Como se ha observado, Villanueva Chang «traduce» el mundo que lo rodea por medio de sus crónicas y perfiles, a menudo tratando de expresar lo inefable por medio de paradojas, antítesis y contradicciones salpicadas de humor, ironía y quizá cierta resignación mal camuflada. Sus personajes son el reflejo de las relaciones humanas en los lugares en los que vive o que visita; al mismo tiempo, las ciudades que describe se hacen eco de las sorprendentes contradicciones de la naturaleza humana. Aunque muchos de los intereses del cronista muestran una mirada internacional, su Perú nativo continúa siendo uno de los principales marcos de referencia de su escritura. En definitiva, la prosa de Villanueva Chang es tan cautivadora porque muestra un espíritu de innovación y frescura, a la vez que se hace eco del ingenio y el carácter lúdico que caracteriza la prosa conceptista de Quevedo. Por esta razón, considero a esta figura clave en el rescate de la crónica y el perfil latinoamericanos un escritor neoconceptista. 


\section{REFERENCIAS BIBLIOGRÁFICAS}

EGAN, Linda (2002). «Play on words: Chronicling the Essay». En Ignacio Corona y Beth E. Jörgensen (editores). The Contemporary Mexican Chronicle. Theoretical Perspectives on the Liminal Genre. Albany: State University of New York Press.

IWASAKI CAUTI, Fernando (2005). Mi poncho es un kimono flamenco. Lima: Sarita Cartonera.

VILLANUEVA CHANG, Julio (1999, 12 de octubre). «Carta a mi abuelo chino. Un cantonés casero y querendón». En El Comercio, Lima.

(1999). Mariposas y murciélagos. Crónicas y perfiles.

Lima: Universidad Peruana de Ciencias Aplicadas.

(2000). «We're not Kansas anymore». En Edmundo Paz Soldán y Alberto Fuguet (editores). Se habla español. Voces latinas en USA. Miami: Editorial Alfaguara.

Mondadori.

(2008). Elogios criminales. México D. F.: Random House

(2011). «La indiscreción de asomarse por la espalda Carta. Horóscopo chino». En Etiqueta Negra, nro. 7, p. 12.

(2011, 16 de junio). «Un chofer de ambulancia que llegaba a tiempo». Consultado el 10 de febrero de 2014 de http://elpais. com/diario/2011/07/16/babelia/1310775137_850215.html

(2012). «El que enciende la luz. ¿Qué significa escribir una crónica en tiempos de crisis de la atención?». E. Darío Jaramillo Agudelo (editor). Antología de crónica latinoamericana actual. Madrid: Editorial Alfaguara. 